\title{
Estudo climatológico dos eventos extremos de precipitação no município de Tracuateua, PA (Brasil)
}

A presente pesquisa avaliou a série de dados meteorológicos de precipitação pluvial e temperatura do ar de 1973 a 2012, referentes à estação meteorológica de Tracuateua, obtidos do Instituto Nacional de Meteorologia. Com a análise dos dados foi possível verificar que há dois períodos de precipitação bem definidos, um mais chuvoso (janeiro a junho), em que a precipitação é mais intensa nos meses de março, abril e maio, e outro menos chuvoso (julho a dezembro), em que a estiagem é maior nos meses de setembro, outubro e novembro. Além disso, foi possível identificar que o ano de 1985 foi o mais chuvoso, associado a evento de La Niña, e o ano de 2010 o menos chuvoso, ligado a evento de El Niño. Assim, a identificação de eventos associados à precipitação através do uso de dados meteorológicos permitirá uma melhor compreensão dos processos envolvidos nos mesmos, podendo inclusive, auxiliar na tomada de decisão de políticas públicas pertinentes.

Palavras-chave: Meteorologia; Fenômenos climáticos; Amazônia.

\section{Climatological study of extreme precipitation events on municipality of Tracuateua, PA (Brazil)}

\begin{abstract}
The present research analyzed a series of meteorological data of pluviometric precipitation and temperature from 1973 to 2012, referring to the meteorologica station of Tracuateua, obtained from the National Institute of Meteorology. With the analysis of the data it was possible to verify that there are two well-defined periods of precipitation, a rainier period (January to June), in which precipitation is more intense in the months of march, april and may, and another less rainy (July to December), in which the drought is greater in the months of september, october and november. In addition, it was possible to identify that the year 1985 was the rainiest year, associated with the La Niña event, and the year 2010 the least rainy, linked to the El Niño event. Thus, the identification of events associated with precipitation through the use of meteorological data will allow a better understanding of the processes involved in them, and may even assist in the decisionmaking of relevant public policies.
\end{abstract}

Keywords: Weather; Climate phenomena; Amazon.

Topic: Meteorologia, Climatologia e Mudanças Climáticas

Reviewed anonymously in the process of blind peer.
Received: 01/01/2021

Approved: 26/01/2021
Amanda Gama Rosa (iD

Universidade Federal do Pará, Brasil

http://lattes.cnpq.br/0895837333331224

http://orcid.org/0000-0002-9053-2777

cezarpinheiroo@hotmail.com

Fabiana da Silva Pereira (it)

Universidade Federal do Pará, Brasil

http://lattes.cnpq.br/2302988398943200

http://orcid.org/0000-0003-2881-6952

cezarpinheiroo@hotmail.com

Alessa Nayhara Mendanha Costa (iD

Universidade Federal do Pará, Brasil

http://lattes.cnpq.br/5318320636675924

http://orcid.org/0000-0003-3539-6423

cezarpinheiroo@hotmail.com
Cézar Di Paula da Silva Pinheiro

Instituto Tecnológico Vale, Brasil

http://lattes.cnpq.br/9477837707374728

http://orcid.org/0000-0003-3946-2379

cezarpinheiroo@hotmail.com
Referencing this:

ROSA, A. G.; PEREIRA, F. S.; COSTA, A. N. M.; PINHEIRO, C. P. S.. Estudo climatológico dos eventos extremos de precipitação no município de Tracuateua, PA (Brasil). Revista Ibero Americana de Ciências Ambientais, v.12, n.1, p.192-201, 2021. DOI:

http://doi.org/10.6008/CBPC2179-6858.2021.001.0016 


\section{INTRODUÇÃO}

O estado do Pará caracteriza-se por apresentar um regime pluviométrico definido por uma estação chuvosa, de dezembro a maio, e uma estação menos chuvosa, de junho a novembro. Durante o seu período chuvoso, o estado apresenta significativo potencial de ocorrência de eventos extremos de precipitação, que podem resultar em enxurradas, inundações, alagamentos, erosões, entre outros. Entre 1991 e 2012 a Defesa Civil Nacional contabilizou no estado 177 ocorrências oficiais de enxurradas, 256 de inundação, 4 de alagamentos e 54 de erosões, as quais se concentraram, principalmente, entre os meses de dezembro a junho (CEPED, 2013). Segundo Barros et al. (2015), o fato ocorre devido a questões de infraestrutura urbana e sua influência direta na capacidade da drenagem pluvial, interferindo no volume e na intensidade do escoamento superficial, o que pode ocasionar alagamentos, inundações e outros.

Nessa perspectiva, recentemente criado, em maio de 1958, o município de Tracuateua, localizado no Nordeste Paraense, ainda apresenta baixa taxa de urbanização $(26,4 \%)$, sendo rodeado por campos naturais que ocupam $20 \%$ do território do município. Apesar de ainda ser considerado predominantemente rural, apresenta uma população estimada em 30.959 pessoas. Por conta de suas características físicas de relevo baixo, encontra-se constantemente sujeito a inundações e alagamentos, que possuem maior potencial de ocorrência na primeira metade do ano, durante o período chuvoso, com precipitação acumulada anual de aproximadamente $2621 \mathrm{~mm}$ (AVIZ et al., 2013a; INMET, 2016). Tal problemática, induzida por eventos extremos de chuva, pode afetar diretamente a paisagem local, assim como a economia do município, baseada, principalmente, em agricultura consorciada, pesca artesanal, criação de animais e extração mineral de areia e seixo (AVIZ et al., 2013a; AVIZ et al., 2013b).

Assim, apesar da baixa ocorrência de desastres naturais associados à precipitação no município (CEPED, 2013), é válida a avaliação do regime pluviométrico e de eventos extremos, de forma a gerar informações sobre a precipitação pluvial na região e a possibilidade de ocorrência dos mesmos, os quais possam servir de base para o planejamento municipal e desenvolvimento de estratégias de mitigação e adaptação. Além disso, o estudo das variáveis hidroclimatológicas também contribui para subsidiar planos de irrigação, planejamento urbano e das atividades agrícolas e econômicas, alternativas para conservação do solo, mudanças climáticas e outros (ROLIM et al., 2007; SOUZA et al., 2014).

Para Varejão-Silva (2005), como forma de se obter determinada análise quantitativa pode-se utilizar o balanço hídrico que, quando empregado de maneira sequencial, contribui para a quantificação das necessidades de irrigação em uma cultura, assim como a possibilidade de relacionar o rendimento das culturas com o déficit hídrico. Dessa forma, "conhecendo os índices hídricos e de aridez relacionados à pluviosidade é possível gerar dados multitemporais que caracterizem as relações entre a atmosfera e o sistema solo-planta" (SOUZA et al., 2014), possibilitando, assim, destacar os períodos anuais que sofrem com perdas hídricas, assim como indicar aqueles com excedente hídrico.

Diante disso, este trabalho objetiva a realização de uma análise da precipitação pluvial e temperatura do ar do município de Tracuateua/PA, no período de 1973 a 2012, caracterizando o clima da região através 
da realização do balanço hídrico. Buscou-se detectar também os eventos extremos de cheia que ocorreram na região dentro desta série de dados, visando conhecer e buscar uma associação destes com eventos climáticos.

\section{METODOLOGIA}

A área de estudo refere-se ao município de Tracuateua, que está localizado na mesorregião do Nordeste Paraense e na microrregião Bragantina (Figura 1). Ocupa uma área de 852 km2, com sede municipal nas coordenadas geográficas $00^{\circ} 46^{\prime} 18^{\prime \prime}$ de latitude sul e $47^{\circ} 10^{\prime} 35^{\prime \prime}$ de longitude a oeste de Greenwich. Ao norte faz limite com o oceano Atlântico, ao leste com o município de Bragança, a oeste com o município de Capanema e Quatipuru e ao sul com Santa Luzia do Pará e Ourém.

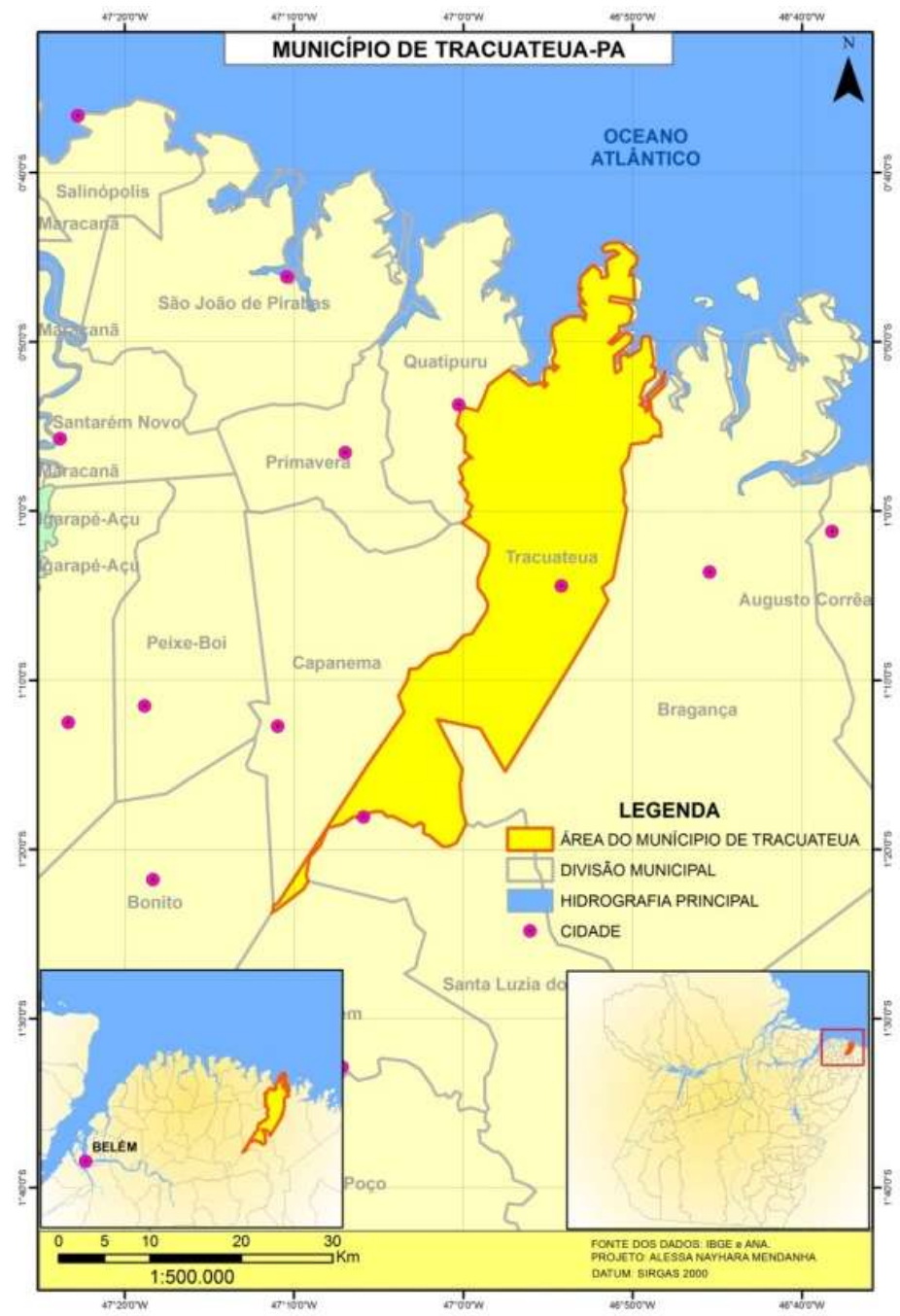

Figura 1: Mapa de localização da área de estudo, Tracuateua/PA

Para as análises das informações, foram utilizados dados diários da série histórica da precipitação pluvial observada no período de 1973 a 2012, referentes à estação meteorológica de Tracuateua (latitude $1,06667^{\circ}$, longitude $-46,9^{\circ}$, altitude de 36 metros) obtidos do Instituto Nacional de Meteorologia (INMET, 2016). Devido à falta de dados em alguns meses da série histórica, optou-se por excluir da análise os anos 1986, 1987, 1988, 1989, 1990, 1992, 2008 e 2009, resultando em uma série de 31 anos de dados. 
A partir da série de dados foi feito o balanço hídrico segundo a metodologia de Thornthwaite et al. (1955). Estabeleceu-se uma retenção de $150 \mathrm{~mm}$ para o cálculo do balanço hídrico. Com os resultados foi feita então a classificação climática de Köppen, simplificada por Setzer (1966), e a classificação climática de Thornthwaite (1948). As modificações feitas por Setzer (1966) na classificação climática de Köppen incluem o tipo climático Am (Tropical monçônico), com chuvas excessivas durante o ano, porém com inverno seco.

A classificação proposta por Thornthwaite (1948) basea-se nos seguintes índices: Índice de umidade (lu), Índice de aridez (la), Índice hídrico (Ih) e o Índice de eficiência térmica (TE).

O Índice de Umidade (lu) é obtido através da relação entre o excesso de água e a evapotranspiração anual (Equação 1):

$I u=((E X C)$ anual $\div($ ETP $)$ anual $)) 100$

Após, calculou-se o Índice de Aridez (la), que é a relação entre a deficiência hídrica e a evapotranspiração potencial (Equação 2):

$$
I a=((D E F) \text { anual } \div(\text { ETP }) \text { anual })) 100
$$

Posteriormente, foi calculado o Índice Efetivo de Umidade ou Índice Hídrico (Ih), que relaciona o Índice de Umidade e o Índice de Aridez (Equação 3):

$$
I h=I u-0,6 \times I a
$$

Foi calculado também o Índice TE (TE, \%) para o Hemisfério Sul (Equação 4).

$$
T E=((E T 11+E T 12+E T 1) \div E T o t) \div 100
$$

Onde, ET11, ET12 e ET1 correspondem aos valores de evapotranspiração de referência dos respectivos meses de novembro, dezembro e janeiro.

Após os cálculos dos índices, determinaram-se os tipos climáticos e subtipos climáticos segundo as tabelas definidas por Thornthwaite (1948).

Para encontrar o número de eventos extremos ocorridos na série histórica do presente estudo calcularam-se os quantis da precipitação diária. Nesse trabalho utilizou-se um percentil de 0,98, ou seja, foram considerados Eventos Extremos De Precipitação Diária (EEPD) aqueles cujo valor da média mensal foi igual ou maior que o percentil $\mathrm{P}=98$, dessa forma foi possível obter um limiar para definir os EEPD.

A fim de analisar a recorrência dos EEPD no município, foram calculadas as probabilidades de ocorrência e períodos de retorno do valor da precipitação do EEPD para os 31 anos de dados, usando a lei de probabilidade logarítmica e a teoria de valores extremos (SCHWAB et al., 1982). O período de retorno (T) e a Probabilidade de ocorrência (Pr) foram obtidos pelas equações a seguir (Equação 5 e 6):

$$
T=(N+1) \div m
$$

Sendo, T o período de retorno, no qual o índice de erosividade é igualado ou superado; N o número de anos de registro de dados, e m o número de ordem do índice de erosividade, quando a série de dados de erosividade é $\operatorname{Pr}=100 \div T$ colocada em ordem decrescente de magnitude.

Sendo: Pr a probabilidade de ocorrência e T o período de retorno.

Utilizou-se o programa OriginPro 8.0 como auxílio na confecção do gráfico da plotagem dos valores determinados das probabilidades de ocorrência, dos períodos de retorno e da curva de distribuição de probabilidade. 


\section{RESULTADOS E DISCUSSÃO}

Na figura 2 é apresentado o extrato do balanço hídrico mensal do município de Tracuateua, no qual se observa que durante um período de seis meses do ano ocorre um excedente hídrico (fevereiro a julho), sendo que o mês de janeiro, apesar de não ocorrer execedente, também não houve deficiência hídrica. Além disso, verificou-se um déficit hídrico de $335 \mathrm{~mm}$ distribuídos no período de agosto a dezembro.

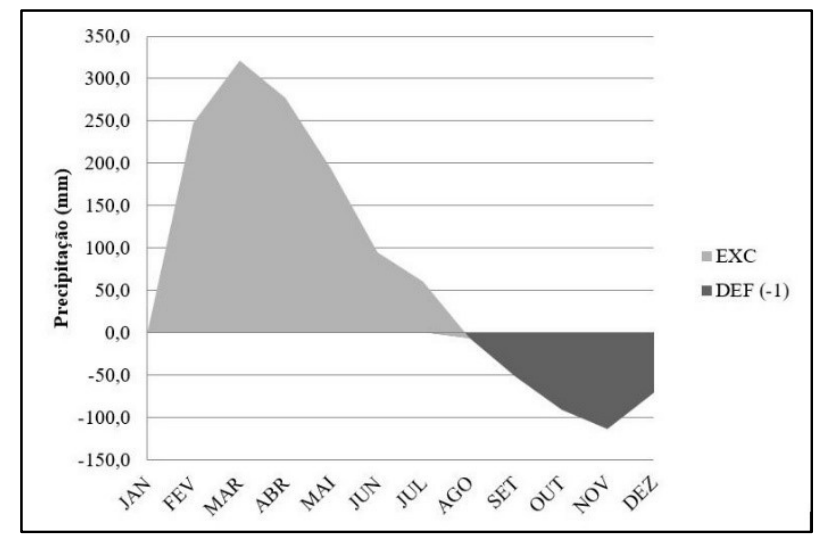

Figura 2: Representação gráfica do balanço hídrico mensal (janeiro a dezembro) do município de Tracuateua/PA.

O clima é definido como tropical de monção $(\mathrm{Am})$ conforme classificação de Köppen, apresentando os messes de Janeiro a Junho com os mais chuvosos. De acordo com a classificação Thornthwaite, tendo como base o Índice Hídrico da região, sua deficiência hídrica, latitude e índice de aridez, o clima é determinado como B3s, classificando assim de forma semelhante à classificação de Köppen, como um clima tropical úmido.

A figura 3 apresenta a variação mensal de precipitação acumulada média e a frequência de EEPD do município entre os anos de 1973 e 2012. Março foi o mês mais chuvoso, com precipitação mensal acumulada média de 446,52 mm, e novembro como menos chuvoso, com precipitação acumulada média de 8,49 mm. O comportamento da precipitação mensal observado se assemelha ao proposto por Moraes et al. (2005), ao analisarem a variação da precipitação no estado do Pará, e ao estudo de Oliveira et al. (2002), o qual abordou sobre a variação da precipitação em Belém, capital do Estado, com transição da estação chuvosa para a menos chuvosa por volta do mês de junho e início da estação chuvosa a partir do mês de dezembro.

De acordo com a figura anterior, observou-se que, o município de Tracuateua, de modo geral, recebe precipitação durante praticamente todo o ano, com chuvas da ordem de $29 \%$, nos meses de dezembro, janeiro e fevereiro, com intensa pluviosidade nos meses março, abril e maio, 48,9\%, significativa contribuição em junho, julho e agosto, 20,5\%, e pequena contribuição em setembro, outubro e novembro, 1,6\%.

O limiar obtido para definir os eventos extremos de precipitação diária a partir do percentil P=98 foi $67,4 \mathrm{~mm}$, o que significa que precipitações iguais ou maiores que $67,4 \mathrm{~mm}$ foram consideradas como de EEPD.

Analisando os casos de eventos extremos de precipitação diária e a variação mensal da precipitação acumulada média, é possível observar que no período chuvoso (dezembro a maio) ocorreram 110 casos de EEPD, enquanto no período menos chuvoso ocorreram apenas 4. Os máximos de precipitação observados, 
durante a estação chuvosa, na série de dados do estudo, e consequentemente aumento do número de EEPD, podem ser explicados pelos sistemas meteorológicos mais importantes que atuam na região Amazônica durante esse período, tais como Zona de Convergência Intertropical (ZCIT) e Zona de Convergência do Atlântico Sul (ZCAS) (CARVALHO et al., 2004; SOUZA et al., 2006).

Com base na observação anual da série de dados de precipitação analisada, conforme Figura 4, verificou-se que o acumulado anual de precipitação variou de $1257 \mathrm{~mm}$ a $4084 \mathrm{~mm}$. O ano de 1985 foi o ano mais chuvoso (com 14 eventos de EEPD), enquanto que 2010 se apresentou como ano menos chuvoso (com nenhum evento de EEPD).

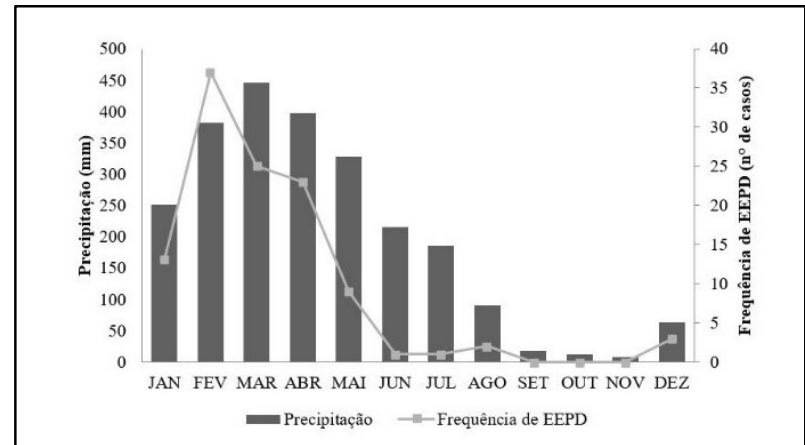

Figura 3: Variação mensal da precipitação acumulada e o número de casos mensais de eventos extremos de precipitação diária acumulado em Tracuateuta/PA, entre os anos de 1973 e 2012.

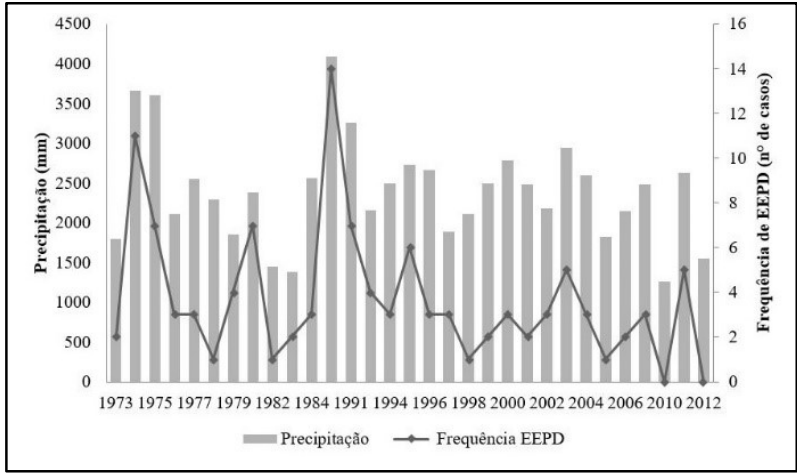

Figura 4: Precipitação Acumulada Anual e Frequência de EEPD no município de Tracuateua/PA, entre os anos de 1973 e 2012.

O ano de 1985 coincide com um evento de La Niña, fase fria do El Niño - Oscilação Sul - ENOS, causado pela diminuição das temperaturas do Pacífico Equatorial, influenciado pela intensificação da célula de Walker, resultando no aumento na precipitação na região Amazônica (OLIVEIRA, 2005). Esse resultado foi confirmado em outros estudos como em Andrade et al. (2003), Leite et al. (2011) e D'Angiolella et al. (2002).

A observação do ano menos chuvoso, 2010, coincide com um dos maiores eventos de seca extrema já registrados. Segundo Borma et al. (2013), a seca de 2010 ocorreu em decorrência da associação de dois eventos: aquecimento anômalo do Pacífico (El Niño) seguido do aquecimento anômalo do Atlântico Norte tropical (AMO - Oscilação Multidecadal do Atlântico). Como consequência de secas extremas, pode ocorrer a estratificação térmica da coluna d'água oceânica, com possíveis implicações à falta de refúgios e diminuição de oxigênio dissolvido para os organismos aquáticos, além da variação na turbidez, diminuição da conectividade dos corpos d'água, entre outras) (BORMA et al., 2013).

Os anos que apresentaram maiores acumulados de precipitação, além de 1985, foram 1974 com 3659,7 mm (com 11 eventos de EEPD), 1975 com 3603,5 mm (com 7 eventos de EEPD), e 1991 com 3252,0 mm (com 7 eventos de EEPD). Todos esses anos, exceto 1991, estiveram sob a influência do fenômeno La Niña, que resulta no aumento da precipitação na região. O ano de 1991, apesar de apresentar um dos maiores acumulados de precipitação, foi um ano de forte ocorrência do fenômeno El Niño, que inibe a precipitação na região. Já os anos que apresentaram o menor volume de chuva e de EEPD, além do ano de 2010, foram 1982 com 1449,6 mm (com 1 evento de EEPD), 1983 com 1381,7 mm (com 2 eventos de EEPD) e 2012 com 1552,6 mm (nenhum evento de EEPD). Esses anos, exceto 2012, estiveram sob a influência do 
fenômeno El Niño.

Analisando os dias de chuva da série de dados, obteve-se que a média anual de dias de chuva corresponde à, aproximadamente, 184 dias, sendo 1985 o ano com mais dias de chuva, chegando a um número de 231 dias, caracterizado por um ano de forte La Niña, como foi explicado anteriormente. Os anos que apresentaram menor número de dias de chuva foram 1979 e 2012, ambos com 153 dias de chuva. 0 ano de 1979 está possivelmente associado ao evento de El Niño de fraca intensidade (1979-1980). O ano de 2012, segundo estudos, não foi ano de El Niño, mas foi um ano de eventos extremos, com temperatura acima da média e extremos de chuva na Amazônia (RITTL, 2012), diferentemente dos dados apresentados neste trabalho, já que não houve casos de EEPD.

A partir do valor do volume médio de precipitação diária de EEPD em cada ano dos dados, foram calculados os períodos de retorno e a probabilidade de ocorrência de eventos de tais portes (Tabela 1). Os valores do período de retorno e da probabilidade de ocorrência, determinados para o maior valor do volume de $\operatorname{EEPD}(133,1 \mathrm{~mm}$, em 1983), foram de 30 anos e 3,33\%, respectivamente. O período de retorno e probabilidade de ocorrência para o menor valor do volume de EEPD (71,1 mm, em 1976) foram, respectivamente, 1,03 anos e 96,67\%. Assim, espera-se que ocorra na área de estudo, com uma probabilidade de 3,33\%, uma precipitação diária com volume igual ou superior a 133,1 mm pelo menos uma vez a cada 30 anos, e que, com uma probabilidade de 96,67\%, ocorra uma precipitação diária com volume igual ou superior a 71,1 mm pelo menos uma vez a cada 1,03 anos. A leitura da curva de período de retorno e probabilidade de ocorrência gerada (Figura 5) permite estimar os períodos de retorno e probabilidades de ocorrência para diferentes valores de volumes de precipitação diária.

Tabela 1: Período de Retorno e Probabilidade de Ocorrência de Eventos Extremos (EE) de Precipitação diária entre os anos de 1973 e 2011.

\begin{tabular}{|c|c|c|c|c|}
\hline Ano & EE (mm/dia) & Médio (m) & $\mathrm{T}$ (anos) & $\mathrm{P}(\%)$ \\
\hline 1983 & 133,1 & 1 & 30,00 & 3,33 \\
\hline 1995 & 107,5 & 2 & 15,00 & 6,67 \\
\hline 2007 & 104,3 & 3 & 10,00 & 10,00 \\
\hline 2011 & 102,7 & 4 & 7,50 & 13,33 \\
\hline 1999 & 100,4 & 5 & 6,00 & 16,67 \\
\hline 1994 & 99,9 & 6 & 5,00 & 20,00 \\
\hline 2005 & 98,6 & 7 & 4,29 & 23,33 \\
\hline 2004 & 98,0 & 8 & 3,75 & 26,67 \\
\hline 1978 & 92,5 & 9 & 3,33 & 30,00 \\
\hline 1974 & 92,3 & 10 & 3,00 & 33,33 \\
\hline 2003 & 91,5 & 11 & 2,73 & 36,67 \\
\hline 1975 & 91,4 & 12 & 2,50 & 40,00 \\
\hline 2002 & 89,0 & 13 & 2,31 & 43,33 \\
\hline 1991 & 87,3 & 14 & 2,14 & 46,67 \\
\hline 1997 & 86,0 & 15 & 2,00 & 50,00 \\
\hline 1998 & 85,9 & 16 & 1,88 & 53,33 \\
\hline 2006 & 85,9 & 17 & 1,76 & 56,67 \\
\hline 1973 & 85,0 & 18 & 1,67 & 60,00 \\
\hline 1977 & 81,4 & 19 & 1,58 & 63,33 \\
\hline 1982 & 80,2 & 20 & 1,50 & 66,67 \\
\hline 1985 & 80,0 & 21 & 1,43 & 70,00 \\
\hline 1984 & 78,2 & 22 & 1,36 & 73,33 \\
\hline 2001 & 76,1 & 23 & 1,30 & 76,67 \\
\hline 1980 & 76,1 & 24 & 1,25 & 80,00 \\
\hline 1979 & 75,0 & 25 & 1,20 & 83,33 \\
\hline
\end{tabular}




\begin{tabular}{lllll}
2000 & 75,0 & 27 & 1,11 & 90,00 \\
\hline 1996 & 74,6 & 27 & 1,11 & 93,33 \\
\hline 1993 & 72,0 & 28 & 1,07 & 93,33 \\
\hline 1976 & 71,1 & 29 & 1,03 & 96,67 \\
\hline
\end{tabular}

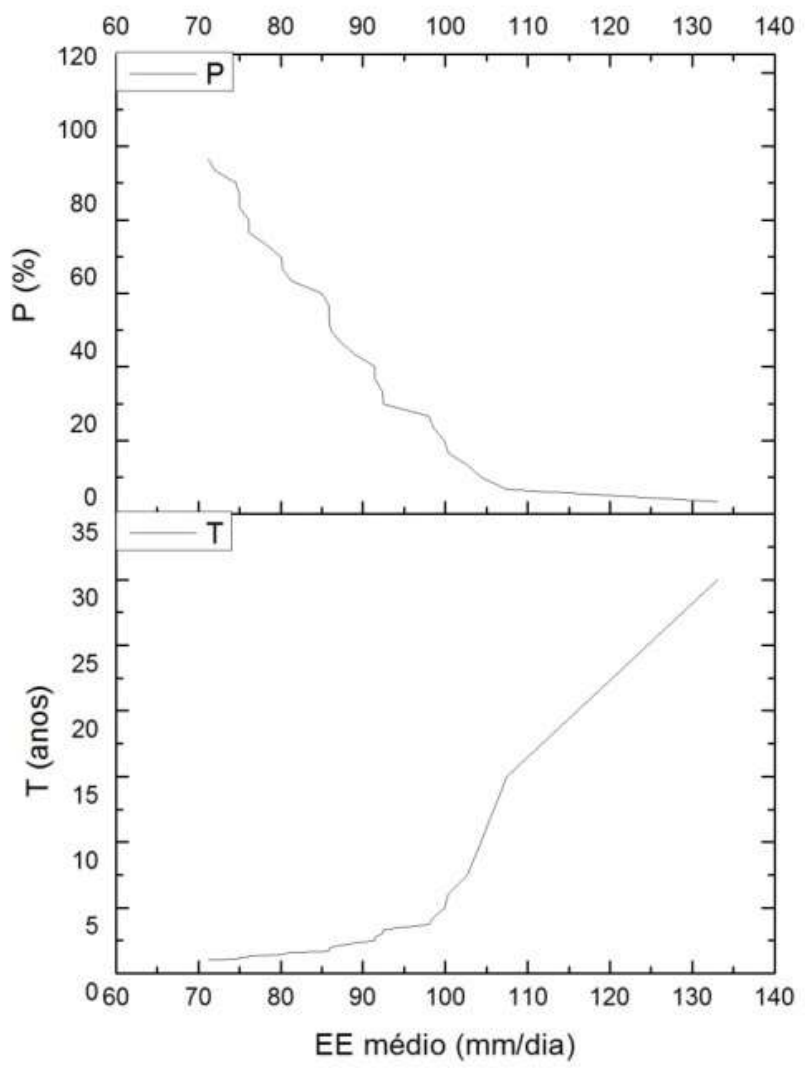

Figura 5: Curva de probabilidade de ocorrência e período de retorno da precipitação diária de EEPD de Tracuateua-PA, com base nos anos de 1973 a 2012.

\section{CONCLUSÕES}

Com a análise dos dados da série histórica adotada no trabalho, é possível verificar que há dois períodos de precipitação bem definidos, um mais chuvoso (janeiro a junho), em que a precipitação é mais intensa nos meses de março, abril e maio, e outro menos chuvoso (julho a dezembro), em que a estiagem é maior nos meses de setembro, outubro e novembro. A precipitação mais intesa no período de março a maio é influenciada pela Zona de Convergência Intertropical (ZCIT), que atua na região principalmente nesse período. Associando a série de dados da variação da precipitação com a ocorrencia de EEPD durante o periodo analisado, observou-se que o período mais chuvoso apresentou 110 casos de EEPD, e o período menos chuvoso 4 casos de EEPD. Essas informações são muito úteis para a população e para o município realizar seu planejamento, visto que eventos extremos têm grande potencial de afetar, principalmente, a produção agrícola do município, baseada na produção de feijão, milho, mandioca e fumo (principais cultivos), que abastecem boa parte da região.

Avaliando todos os anos da série foi possível identificar alguns anos mais e menos chuvosos, como o ano de 1985, mais chuvoso, associado à evento de La Niña, e o ano de 2010, menos chuvoso, ligado à evento de El Niño. O ano de 1985 apresentou 14 casos de EEDP, e o ano mais seco, 2010, não apresentou nenhum caso de EEPD. 
A classificação climatica foi realizada segundo duas metodologias, Thornthwaite e Köppen. O clima foi classificado como do tipo Am, tropical monçônico, segundo Köppen, com temperatura média do mês mais frio superior a $18^{\circ} \mathrm{C}$, precipitação total anual média superior a $1500 \mathrm{~mm}$ e precipitação do mês mais seco menor que $60 \mathrm{~mm}$. Foi também classificado como B3s, segundo Thornthwaite, como um clima tropical úmido (ROLIM, 2007).

Avaliando o período de retorno e a probabilidade de ocorrência de precipitações de EEPD, espera-se que ocorra na área de estudo, com uma probabilidade de 3,33\% uma precipitação diária com volume igual ou superior a 133,1 mm pelo menos uma vez a cada 30 anos, e que, com uma probabilidade de $96,67 \%$, ocorra uma precipitação diária com volume igual ou superior a 71,1 mm pelo menos uma vez a cada 1,03 anos.

Assim, a identificação de eventos associados à precipitação através do uso de dados meteorológicos permitirá uma melhor compreensão dos processos envolvidos nos mesmos. Podendo inclusive, auxiliar na tomada de decisão de políticas públicas pertinentes.

AGRADECIMENTOS: À Profa. Isabel Vitorino pelo apoio e ao Instituto Nacional de Meteorologia - INMET pelo fornecimento de dados para o trabalho.

\section{REFERÊNCIAS}

ANDRADE, A. R.; NERY, J. T.. Análise da precipitação pluviométrica diária, mensal e interanual da bacia hidrográfica do Rio Ivaí, Brasil. Investigaciones Geográficas, Cidade do México, v.52, n.1, p.7-30, 2003.

AVIZ, F. R. S.; PINHEIRO, M. F. D.. A ausência de governança ambiental e o agravamento de problemas causados pela exploração de recursos minerais em Tracuateua/PA. In: ENCONTRO NACIONAL DE PESQUISADORES EM GESTÃO SOCIAL, 7. Anais. Belém: ENAPEGS, 2013a.

AVIZ, F. R. S.; PINHEIRO, M. F. D.; MENDONÇA, M. S.; MOREIRA, A. M.. Análise ambiental dos campos naturais de Tracuateua/PA: as territorialidades produtivas e seus possíveis impactos. In: CONGRESSO BRASILEIRO DE GESTÃO AMBIENTAL, 4. Anais. Salvador: ConGeA, 2013b.

BARROS, M. V. F.; MENDES, C.; CASTRO, P. H. M.. Vulnerabilidade socioambiental à inundação na área urbana de Londrina/PR. Confins, n.24, 2015. DOI:

http://doi.org/10.4000/confins.10228

BORMA, L. S.; NOBRE, C. A.. Secas na Amazônia: Causas e Consequências. São Paulo: Oficina de Textos, 2013.

CARVALHO, L. M. V.; JONES, C.; LIEBMANN, B.. The South Atlantic Convergence Zone: intensity, form, persistence and relationships with intraseasonal to interanual activity and extreme rainfall. Journal of Climate. New York, v.17, n.1, p.88-108, 2004. DOI: https://doi.org/10.1175/15200442(2004)017\%3C0088:TSACZI\%3E2.0.CO;2

CEPED. Centro Universitário de Estudos e Pesquisas sobre Desastres. Atlas brasileiro de desastres naturais: 19912012. Volume Pará. 2 ed. Florianópolis: CEPED UFSC, 2013.
D'ANGIOLELLA, G.; REBELLO, E.; ANUNCIAÇÃO, Y.; BALEEIRO, C.. Influência dos fenômenos acoplados oceano-atmosfera na precipitação de Cruz das Almas, Bahia. Bahia Agrícola, v.5, n.1, p.49-52, 2002.

INMET. Instituto Nacional de Meteorologia. Normais Climatológicas do Brasil 1961-1990. INMET, 2016.

LEITE, M. D. A.; TEIXEIRA, G. L. G.; CHACALTANA, J. T. G.; SILVA, M. R. L. F.. Descrição das variabilidades nas anomalias de TSM de 1985 a 2005 para a porção noroeste do Atlântico Sul. In: SIMPÓSIO BRASILEIRO DE SENSORIAMENTO REMOTO, 15. Anais. Curitiba: SBSR, 2011. p.7160-67.

MORAES, B. C. D.; COSTA, J. M. N. D.; COSTA, A. C. L. D.; COSTA, M. H.. Variação espacial e temporal da precipitação no estado do Pará. Acta Amazônica, v.35, n.2, p.207-214., 2005. DOI: http://doi.org/10.1590/S004459672005000200010

OLIVEIRA, G.. El Niño/ La Niña: Tópicos em Meio Ambiente e Ciências Atmosféricas. São José dos Campos: INPE, 2005.

OLIVEIRA, M. C. F.; ABREU, J. R. R.; BARROS, A. N. F.; BEZERRA, A. C. N.; MACHADO, J. R. S.; NETO, B. S.. Tendência mensal e anual das chuvas em Belém-PA, de 1896 a 2000 (105 anos). In: CONGRESSO BRASILEIRO DE METEOROLOGIA, 12. Anais. Foz do Iguaçu: CBMET, 2002. p.832-35.

RITTL, C.. Eventos climáticos no Brasil: impactos, ciência e políticas públicas. WWF, 2012.

ROLIM, G. D. S.; CAMARGO, M. B. P. D.; LANIA, D. G.; MORAES, J. F. L. D.. Classificação climática de Köppen e de 
Thornthwaite e sua aplicabilidade na determinação de zonas agroclimáticas para o Estado de São Paulo. Bragantia, v.66, n.4, p.711-720, 2007.

SCHWAB, G. O.; FREVERT, R. K.; EDMINSTER, T. W.; BARNES, K. K.. Soil and water conservation engineering. Soil Science, v.134, n.2, p.146, 1982.

SETZER, J.. Atlas Climático e Ecológico do Estado de São Paulo. São Paulo: Comissão Interestadual da Bacia ParanáUruguai, 1966.

SOUZA, S. O.; CORREA, W. S. C.; FILETI, R. B.; VALE, C. C.. Balanço Hídrico da Bacia Hidrográfica do Rio Caravelas (BA) como Subsídio ao Planejamento Agrícola. Revista Brasileira de Geografia Física, v.07, n.01, p.083-092, 2014.
SOUZA, E. B.; ROCHA, E. J. P.. Diurnal variations of rainfall in Bragança/PA (eastern Amazon) during rainy season: mean characteristics and extreme events. Revista Brasileira de Meteorologia, São José dos Campos, v.21, n.3, p.142-152, 2006.

THORNTHWAITE, C. W.. An approach toward a rational classification of climate. Geographical Review, New York, v.38, n.1, p.55-94, 1948.

THORNTHWAITE, C. W.; MATHER, J. R.. The water balance centerton: Drexel institute of technology. Publications in climatology, v.8, n.1, 1955.

VAREJÃO-SILVA, M. A.. Meteorologia e Climatologia. Recife, 2005.

A CBPC - Companhia Brasileira de Produção Científica (CNPJ: 11.221.422/0001-03) detém os direitos materiais desta publicação. Os direitos referem-se à publicação do trabalho em qualquer parte do mundo, incluindo os direitos às renovações, expansões e disseminações da contribuição, bem como outros direitos subsidiários. Todos os trabalhos publicados eletronicamente poderão posteriormente ser publicados em coletâneas impressas sob coordenação da Sustenere Publishing, da Companhia Brasileira de Produção Científica e seus parceiros autorizados. Os (as) autores (as) preservam os direitos autorais, mas não têm permissão para a publicação da contribuição em outro meio, impresso ou digital, em português ou em tradução. 